\title{
Plasmid-based gene therapy of diabetes mellitus
}

\author{
GJ Prud'homme ${ }^{1}$, R Draghia-Akli ${ }^{2}$ and Q Wang ${ }^{3}$ \\ ${ }^{1}$ Department of Laboratory Medicine, St Michael's Hospital and University of Toronto, Ontario, Canada; ${ }^{2}$ ADViSYS Inc., The \\ Woodlands, TX, USA and ' ${ }^{3}$ Division of Endocrinology and Metabolism, St Michael's Hospital and University of Toronto, Ontario, \\ Canada
}

Type I diabetes mellitus (T1D) is due to a loss of immune tolerance to islet antigen and thus, there is intense interest in developing therapies that can re-establish it. Tolerance is maintained by complex mechanisms that include inhibitory molecules and several types of regulatory $T$ cells (Tr). $A$ major historical question is whether gene therapy can be employed to generate Tr cells. This review shows that gene transfer of immunoregulatory molecules can prevent T1D and other autoimmune diseases. In our studies, non-viral gene transfer is enhanced by in vivo electroporation (EP). This technique can be used to perform DNA vaccination against islet cell antigens and when combined with appropriate immune ligands results in the generation of $\operatorname{Tr}$ cells

Keywords: diabetes; DNA vaccination; EP

\section{Introduction}

In recent years, there has been considerable interest in the development of gene therapy approaches for the treatment of endocrine diseases. As type I diabetes (T1D) results from autoimmunity against pancreatic islet beta cells, causing the loss of these cells, therapies have to both block autoimmunity and restore the beta-cell mass. In this review, we present evidence that this can be achieved, at least in part, by plasmid-based gene therapy in preclinical disease models. Furthermore, both T1D and type II diabetes (T2D), and their associated complications, are amenable to gene therapy.

The success of gene therapy depends on the efficient insertion of genes into appropriate target cells, without causing cell injury, oncogenic mutation or inflammation. In an ideal setting, one should also be able to readminister the vector several times, especially for the treatment of chronic diseases. Few vector technologies meet all of these requirements. Although the majority of gene therapy studies have been performed with viral vectors, they have serious limitations in terms of immunogenicity and pathogenicity. Non-viral (primarily plasmid-based) gene therapy raises fewer safety concerns, ${ }^{1}$ and is not hampered by immunogenicity to vector-specific sequences or products, permitting re-

Correspondence: Professor GJ Prud'homme, St Michael's Hospital, Department of Laboratory Medicine, Room 2013CC, 30 Bond Street, Toronto, Ontario, Canada M5B1W8.

E-mail: prudhommeg@smh.toronto.on.ca

Received 1 November 2006; revised 27 November 2006; accepted 28 November 2006; published online 11 January 2007 and protection against T1D. In vivo EP can also be applied for non-immune therapy of diabetes. It can be used to deliver protein drugs such as glucagon-like peptide 1 (GLP-1), leptin or transforming growth factor beta (TGF- $\beta$ ). These act in T1D or type II diabetes (T2D) by restoring glucose homeostasis, promoting islet cell survival and growth or improving wound healing and other complications. Furthermore, we show that in large animals EP can deliver peptide hormones, such as growth hormone releasing hormone (GHRH). We conclude that the non-viral gene therapy and EP represent a safe and efficacious approach with clinical potential.

Gene Therapy (2007) 14, 553-564. doi:10.1038/sj.gt.3302907; published online 11 January 2007 administration. Long-term expression is possible without chromosomal incorporation following in situ muscletargeted gene transfer owing to the stable postmitotic phenotype of the skeletal muscle fiber. ${ }^{2,3}$ A major limitation of non-viral gene therapy has been low transfection efficiency, but this can be ameliorated sufficiently to rival viral vectors in many applications. One of the most versatile and efficient methods of enhancing gene transfer involves the application of electric field pulses after the injection of nucleic acids (DNA, RNA and/or oligonucleotides) into tissues. ${ }^{4}$ This approach is frequently denoted in vivo electroporation (EP) and results in a transient increase in membrane permeability, presumably through the formation of membrane pores, allowing direct entry of macromolecules. ${ }^{5}$ Furthermore, the application of electric current has an electrophoretic effect, which is thought to favor plasmid entry into cells. In diabetes, plasmid-based gene transfer, especially when enhanced by EP, can be applied to either induce immune tolerance (in T1D), increase islet beta-cell mass, deliver insulin and other endocrine hormones, augment glucose-dependent insulin production, promote wound healing or ameliorate other complications of disease. Most studies have been performed in rodents, but we also discuss how this therapeutic strategy can be applied to large animals and humans.

\section{Non-viral gene therapy vectors}

Almost all the non-viral vectors employed thus far are expression plasmids, which have been designed for high 
Table 1 Studies comparing i.m. injection to i.m. injection with EP in various species

\begin{tabular}{|c|c|c|c|c|c|}
\hline Plasmid conc. & Target muscle & Transgene & Animal model & Fold increase & Reference \\
\hline $0.05 \mathrm{mg}$ & Anterior tibialis & IL-5 & Mouse & $57-118$ & 80 \\
\hline $0.015 \mathrm{mg}$ & Gastrocnemius, rectus femoris, tibialis cranialis & Luciferase & Mouse & $215-1120$ & 5 \\
\hline $0.2 \mathrm{mg}$ & Tibialis cranialis & Epo & Mouse & $10-100$ & 81 \\
\hline $0.05 \mathrm{mg}$ & Quadriceps & Luciferase & Mouse & $10-70$ & 82 \\
\hline $0.02 \mathrm{mg}$ & Gastrocnemius & Luciferase & Mouse & 119 & 83 \\
\hline $0.015 \mathrm{mg}$ & Rectus femoris, triceps brachii, tibialis cranialis & Luciferase & Rat & $162-186$ & 5 \\
\hline $0.05 \mathrm{mg} / \mathrm{kg}$ & Quadriceps & SEAP & Rat & 120 & 84 \\
\hline $0.1 \mathrm{mg}$ & Tibialis anterior & $\beta$-Gal & Rat & 30 & 85 \\
\hline $0.015 \mathrm{mg}$ & Rectus femoris, triceps brachii, tibialis cranialis & Luciferase & Rabbit & $4310-32025$ & 5 \\
\hline $0.3 \mathrm{mg}$ & Tibialis & SEAP & Monkey & $400-4700$ & 86 \\
\hline $0.1 \mathrm{mg}$ & Quadriceps & Luciferase & Pigs & $100-1000$ & 87 \\
\hline
\end{tabular}

Abbreviation: i.m., intramuscular.

expression when delivered to striated muscle or other cells. ${ }^{4}$ The construction of these vectors is simple and straightforward. The most successful plasmids carry a strong ubiquitous (often the human cytomegalovirus (CMV) immediate-early enhancer promoter (IE-EP)) or tissue-specific promoter, ${ }^{6}$ an intron (such as CMV intron A), a multiple cloning site for insertion of the gene of interest and an appropriate transcriptional terminator segment. A tissue-specific promoter has the advantage of restricting expression of the vector to the desired target tissue. Furthermore, viral promoters are sensitive to cytokines and may be turned off rapidly in the presence of inflammation, whereas tissue-specific promoters are usually insensitive to this and can be expressed for months or years.

Gene transfer can be accomplished in almost any tissue by EP, but the muscle is by far the favorite target. ${ }^{4,7-12}$ Indeed, plasmid delivery into muscle (usually by needle injection) in conjunction with EP allows the muscle to be used as a bioreactor for the persistent, long-term production and secretion of proteins into the blood stream. EP can be performed through electrodes implanted into muscle or other tissues, or applied externally to these tissues at the site of DNA injection. Following entry into the cell, a fraction of the injected plasmid vectors reach the nucleus, where vector-driven transcription occurs. ${ }^{13}$ The plasmid must overcome several barriers before entering the nucleus and, although the process is not completely understood, EP facilitates this migration. ${ }^{14}$

Some recent review articles address the technical aspects of EP-enhanced non-viral gene therapy.,11,15 After in vivo gene electrotransfer into skeletal muscle, the duration of gene expression can range from several weeks to well over a year, depending on the construct and species. The more than 300 reported studies using direct intramuscular (i.m.) injection of plasmid followed by EP provide the evidence that adequate levels of secreted, and in some case intracellular, proteins can be achieved using plasmids in a simple, safe and efficient manner, with significant potential for gene transfer and vaccination for large animals and humans.

An increase in transgene expression by several orders of magnitude has been confirmed, following i.m. plasmid injection and EP. ${ }^{5}$ Data have clearly demonstrated that EP following i.m. plasmid injection in mice, pigs, non-human primates and other mammals has resulted in an average 10- to 1000-fold increase in transgene uptake and expression (in some circumstances up to 32000 -fold increase), depending on the target muscle, injection volume and plasmid quantity (Table 1).

$\mathrm{EP}$ is an ideal tool when immune modulators, such as cytokines and antibodies, need to be expressed systematically at higher levels. However, EP may not be the most optimal tool to increase antigen-specific regulatory T-cells ( $\mathrm{Tr}$ or Treg) to prevent or treat autoimmune diseases. High antigenic doses often may result in T-cell deletion, whereas lower doses appear to expand Tr cells. However, as described later, our recent work shows that Tr cells can be induced by EP-enhanced DNA vaccination when an immunomodulatory vector (covaccine) is included.

\section{Potential hazards}

The safety of DNA administered by injection into the muscle has been evaluated in humans and in many animal species. ${ }^{4}$ All results indicate that plasmid DNA is generally well tolerated and that there are no serious adverse effects associated with either plasmid backbones or different active expression cassettes. Some adverse effects, however, include muscle contraction at the time of current application and local pain, which is usually not severe.

One historical concern was that, after injection, the DNA would integrate into the recipient host's chromosomes, leading to mutagenesis and potentially insertion carcinogenesis. Animal studies involving plasmid DNA injections have shown that mutations from a potential integration event would be extremely infrequent, about 3000 times lower than the spontaneous mutation rate for mammalian genomes. ${ }^{16-18}$ However, in the case of DNA vaccination against foreign antigens, it is of some concern that transfected muscle cells may be attacked and injured by the immune system, and this has been reported. ${ }^{4,7,8}$ A related concern is the production of pathogenic anti-DNA antibodies, potentially induced by plasmid DNA and its immunostimulatory sequences (ISS), but the risk appears relatively small. ISS consist of unmethylated CpG-containing bacterial DNA sequences, which bind to Toll-like receptor 9 (TLR9) of lymphoid cells and activate innate immune responses. ${ }^{19,20} \mathrm{~B}$ cells 
have mechanisms that prevent autoantibody production in response to $\mathrm{CpG}$ stimulation, although this tolerance can be broken. In lupus-prone mice, anti-doublestranded DNA (dsDNA) antibody titers are increased by plasmid DNA administration. However, there have been contradictory reports of the effects on disease. Some authors have reported that injection of bacterial DNA (carrying CpG-ISS) in lupus-prone mice reduced the severity of disease, whereas others have reported detrimental effects. ${ }^{4}$ Evidently, the effects of CpG motifs on lupus should be analyzed further, and special caution should be exercised in administering CpG-bearing plasmids to patients with autoimmune diseases.

\section{The autoimmune basis of T1D}

Endocrine organs are the most frequent targets of autoimmunity, resulting from a breakdown of either central or peripheral immune tolerance. Numerous studies have confirmed that T1D in rodents and humans is a T-celldependent autoimmune disease, resulting from defects in immune tolerance and $\mathrm{T}$ cell regulation. ${ }^{21,22}$ The mechanisms that regulate tolerance are complex and act at the level of both innate and adaptive immunity. Here, we will consider primarily the mechanisms that regulate adaptive immunity in $\mathrm{T}$ lymphocytes, that is, T-helper cells (Th1 and Th2), cytotoxic T lymphocytes (CTLs) and Tr cells. In the case of T cells, central tolerance is acquired in the thymus, where thymocytes undergo positive and negative selection. A failure to achieve negative selection results in the release of $\mathrm{T}$ cells that are autoreactive and are highly likely to cause autoimmunity. There are few autoimmune diseases in which a failure of central tolerance can be clearly implicated, but this has been noted in patients with mutations of the autoimmune regulator (AIRE) gene, which encodes a transcription factor (Table 2). ${ }^{23,24}$ The AIRE gene controls the expression and presentation of many self-antigens, such as insulin, in thymic medullary epithelial cells and is critically important for the elimination of self-reactive $\mathrm{T}$ cells. However, most autoimmune diseases appear to result from defects in peripheral tolerance. ${ }^{21}$ Extrathymic mechanisms of tolerance are important because not all auto-reactive $\mathrm{T}$ cells are deleted in the thymus. Indeed, some potentially autoaggressive $T$ cells (perhaps with low affinity for self-antigens) are normally released from the thymus and must be controlled by various mechanisms. This includes the expression of immunoinhibitory molecules by $\mathrm{T}$ cells, such as CTLA-4 and PD-1, and the production of regulatory cytokines, such as transforming growth factor $\beta$ (TGF- $\beta$ ) and interleukin 10 (IL-10) by either T cells or other cells. ${ }^{21}$

Immunity is further controlled by various types of Tr cells. ${ }^{25-28}$ They can be broadly divided into two subsets, that is, the natural $\mathrm{Tr}$ cells of $\mathrm{CD}^{+}{ }^{+} \mathrm{CD} 25^{+} \mathrm{Foxp}^{+}$phenotype, which in humans constitute $2-3 \%$ of peripheral blood mononuclear cells and the stimulation-induced (or adaptive) Tr cells identified in various models of inflammation, alloreactivity or autoimmunity. In contrast to natural $\mathrm{Tr}$ cells, induced Tr cells probably differentiate from naïve $\mathrm{CD} 4^{+} \mathrm{CD} 25^{-}$ $\mathrm{T}$ cells and act principally by secreting regulatory cytokines, such as TGF- $\beta 1$ (Th3 cells) or IL-10 and TGF- $\beta 1$ (Tr1 cells). ${ }^{29}$

Natural CD $4{ }^{+} \mathrm{CD} 25^{+} \mathrm{Tr}$ cells, released as differentiated Tr cells from the thymus, play an important role in limiting autoimmunity and appear to act by a cytokineindependent, but contact-dependent, mechanism. ${ }^{25}$ The gene Foxp3, encoding a transcriptional regulator, appears to be necessary for the differentiation of natural Tr cells and at least some types of induced Tr cells. ${ }^{28}$ For instance, a Foxp3 mutation in scurfy mice results in the absence of these Tr cells and early death from a multiorgan inflammatory disorder. One of the most severe autoimmune diseases in humans is a severe X-linked autoimmune syndrome (denoted IPEX) determined by mutations of Foxp3 (Table 2). ${ }^{29-31}$

\section{Autoimmune diabetes in NOD mice}

Most of our knowledge of autoimmunity in T1D comes from the study of animal models, particularly non-obese diabetic (NOD) mice. In these mice, the disease is more severe in females and occurs because insulin-producing $\beta$-cells are destroyed following infiltration of islets of Langerhans by macrophages and islet-cell antigenreactive, auto-aggressive $\mathrm{T}$ cells. ${ }^{32,33}$ The islet inflammatory process is termed insulitis and begins as a relatively benign peri-islet infiltrate (peri-insulitis), which eventually evolves into an invasive and destructive intra-islet lymphocytic infiltrate. The disease can be adoptively transferred with $\mathrm{T}$ lymphocytes, provided both $\mathrm{CD}^{+}$ and $\mathrm{CD}^{+}$cells are included. Moreover, diabetogenic T-cell clones, reactive to various islet antigens, have been isolated.

Over time, there is a progressive loss of $\mathrm{Tr}$ cell activity in NOD mice, as well as increased resistance of autoaggressive effector $\mathrm{T}$ cells to the action of residual $\mathrm{Tr}$ cells. ${ }^{22}$ This decreased effectiveness of Tr cells coincides with the evolution of insulitis from a peri-insulitis to true

Table 2 Multi-organ inflammatory diseases associated with failed tolerance induction

\begin{tabular}{llll}
\hline Deficient protein (species $^{\mathrm{a}}$ ) & Disease name & Target tissues of autoimmunity & Tolerance defect \\
\hline AIRE $^{\mathrm{b}}(\mathrm{h}, \mathrm{m})$ & APECED & Multi-organ (polyendocrinopathies) & Central, thymus (reduced clonal deletion) \\
TGF- $\beta 1(\mathrm{~m})$ & Gene KO & Multi-organ (early death) & Peripheral (Tr and other cells) \\
CTLA-4 $(\mathrm{m})$ & Gene KO & Multi-organ (early death) & Peripheral (T cell hyperactivity) \\
Foxp3 $(\mathrm{h}, \mathrm{m})$ & IPEX & Multi-organ (early death) (very early T1D) & Peripheral (lack of Tr cells) \\
\hline
\end{tabular}

${ }^{a} \mathrm{~m}$, mouse; h, human.

bAbbreviations: AIRE, autoimmune regulator (transcription factor); APECED, autoimmune polyendocrinopathy-candidiasis-ectodermal dystrophy syndrome; CTLA-4, cytotoxic T lymphocyte antigen 4 (also denoted CD152); IPEX, immunodysregulation, polyendocrinopathy, enteropathy, X-linked syndrome; Foxp3, Forkhead box p3 (transcription factor); T1D, type I diabetes mellitus. 
insulitis, resulting in beta-islet cell destruction and the clinical onset of diabetes.

\section{Therapy with cytokines or cytokine inhibitors in autoimmune diabetes}

Diabetes in NOD mice can be prevented by gene therapy (or protein therapy) with regulatory cytokines, that is, either IL-4 (or IL-4/Ig fusion), IL-10 or TGF- $\beta$. These cytokines can be delivered by either viral or non-viral gene therapy approaches. We have reviewed these studies previously ${ }^{4}$ and will mention them only briefly. Most likely, these therapies act through a direct inhibitory effect on macrophages, $\mathrm{T}$ cells or other effector cells. They may also induce a shift from Th1 to Th2 differentiation (Th2 cells being less pathogenic) or increase the differentiation or activity of adaptive $\mathrm{Tr}$ cells. Indeed, these effects are not mutually exclusive. A limitation of therapy with cytokines, however, is that they have systemic effects, might promote Th2-dependent allergic reactions or exert toxic and/or other undesirable effects.

Some of these limitations can be diminished or obviated by administering inhibitors of inflammatory cytokines, instead of regulatory cytokines. These inhibitors are much less likely to produce adverse effects. Indeed, the transfer of cDNA encoding cytokine inhibitors protects against several autoimmune diseases.7,8 IL-12 and interferon- $\gamma$ (IFN- $\gamma$ ) are inflammatory cytokines that are detrimental in some autoimmune diseases and, consequently, their neutralization is likely to be protective. These two cytokines are functionally related, as IL-12 induces IFN- $\gamma$ production by T cells and natural killer (NK) cells, whereas IFN- $\gamma$ mediates or augments many of the effects initiated by IL-12.

To neutralize IFN- $\gamma$, we constructed a plasmid vector that encodes a soluble IFN- $\gamma$ receptor IgG1-Fc fusion protein (IFN- $\gamma \mathrm{R} / \mathrm{IgG} 1-\mathrm{Fc}$ ). ${ }^{34,35}$ In vivo administration of our IFN- $\gamma \mathrm{R} / \mathrm{IgG} 1-\mathrm{FC}$ construct almost completely blocked IFN- $\gamma$ activity. In agreement with the postulated pathogenic role of IFN- $\gamma$, this plasmid was protective in both natural and drug-induced models of autoimmune diabetes. $^{34,35}$ In each case, therapy reduced the severity of insulitis and the frequency of diabetes. Gene therapy using this hybrid construct was also quite effective in the treatment of murine lupus, particularly when in vivo EP was applied to improve gene transfer. ${ }^{36}$

As in the case of cytokine therapy, anti-cytokine therapy lacks specificity and its effects are systemic. Thus, patients treated with cytokine inhibitors are likely to be partially immunosuppressed and more susceptible to infections, as shown in the therapy of rheumatoid arthritis with anti-tumor necrosis factor- $\alpha$ (TNF- $\alpha$ ) agents. $^{37,38}$ Ideally, immunotherapy should suppress only the immune responses directed against the target antigen. Although difficult to achieve, this targeted immunosuppression might be possible with some forms of antigen therapy as outlined below.

\section{Applications of DNA vaccination}

DNA vaccination has been studied as a means of generating immunity against the antigens of infectious agents or tumors ${ }^{39-43}$ owing to the simplicity, versatility and safety of the method. In the vast majority of cases, DNA has been delivered in the form of an expression plasmid, either naked or complexed to other molecules, although other types of vectors can be used. Plasmids can be delivered by i.m., intradermal (i.d.)/epidermal or subcutaneously (s.c.) injections, or by oral (e.g., with bacterial carrier), pulmonary (aerosols) or other routes (e.g., vaginal). Plasmid-encoded antigen is presented by bone marrow-derived antigen-presenting cells (APCs), which are most likely dendritic cells (DCs) or macrophages. Compared with other methods, the advantage of DNA vaccination is that delivery of the antigen gene can easily be coupled to the delivery of any number of genes that modify the immune response. Moreover, antigen presentation occurs through both the major histcompatibility complex (MHC) class I or class II-restricted pathways, and all arms of the immune response are activated, that is, Th cells, CTLs and humoral immunity.

DNA vaccination has been effective in rodents, but results have been less impressive in large animals and humans. Consequently, many approaches have been investigated to improve these vaccines (reviewed in Prud'homme $^{41}$ ). One of the most effective has been in vivo EP. Indeed, the application of EP, regardless of the site of injection, should favor the transfection of a greater variety of cells, including APCs. Furthermore, mild tissue damage, as may be induced by EP, is thought to provoke an influx of APCs, induce danger signals (e.g., inflammatory mediators and chemokines) and enhance the release of antigen from injured cells, thereby improving antigen presentation.

\section{DNA vaccination against T1D}

One avenue of inducing antigen-specific tolerance involves coupling $\mathrm{T}$-cell recognition of autoantigens with the delivery of signals that either turn T cells off or induce their differentiation to a nonpathogenic type. It is not easy to accomplish this by conventional antigen therapy, but DNA vaccination provides this opportunity. DNA vaccines are usually immunostimulatory, inducing immunity against foreign or even self-antigens (especially of tumors). Nevertheless, DNA vaccines have been used to protect against experimental autoimmune encephalomyelitis (EAE), T1D and other forms of autoimmunity. ${ }^{39,40}$

DNA vaccination is essentially a form of antigen therapy, and it is critically important to choose the correct target antigen. Several islet-cell antigens have been recognized: proinsulin/insulin, glutamic acid decarboxylase isoforms 65 and 67 (GAD65, GAD67), insulinoma associated-2 (IA-2) and related tyrosine phosphatases, glucose-6-phosphatase catalytic subunitrelated protein (IGRP) and several others. ${ }^{32,33}$ GAD isoforms and insulin are the best studied, but the relative importance of the various islet antigens has not been clear. Insulin is an autoantigen in T1D in humans as has been shown in previous studies, ${ }^{44,45}$ and NOD mice, and has the greatest potential for antigen therapy. In NOD mice, the insulin peptide B:9-23 is the primary target of the immune system. Administration of insulin, or its B:923 peptide, to NOD mice orally, nasally or intravenously (i.v.) may protect them from diabetes, possibly by biasing 
responses to a Th2 type or inducing other Tr cells. Only the insulin B-chain prevents diabetes, and furthermore, T1D can be accelerated in some cases. ${ }^{46-48}$ In other cases, immunization of NOD mice using insulin B:9-23 peptide has resulted in fatal anaphylaxis. ${ }^{49}$ Antigen therapy has been reported to be effective only when administered in the pre-diabetic phase, although we have been able to reverse disease by DNA vaccination against islet antigens in the first 2 weeks after onset of diabetes, but not later (unpublished observations). Unfortunately, the diabetes prevention trial (DPT-1), where insulin was administered s.c., i.v. or orally to individuals at risk of developing diabetes, has yielded negative results outlining the need for new approaches. A potential alternative is DNA vaccination, and, indeed, some DNA vaccination approaches have been protective in murine models of T1D.

Several investigators have reported protection against autoimmune diabetes by DNA vaccination against isletcell antigens (insulin, GAD65 or other) in NOD mice or other diabetes models (Table 3 ). ${ }^{50-61}$ In the vast majority of cases, DNA was delivered i.m. without electroporation. However, injecting antigen-encoding plasmids alone has produced variable and unpredictable results. In many cases, protection against diabetes was accompanied by a Th2 bias in the T-cell response to islet autoantigens. For instance, investigators have co-injected genes encoding cytokines such as IL-4 and/or IL-10 to promote a shift from a pathogenic Th1 to a protective Th2 response (Table 3 ). However, it should be noted that Th2 cells can be pathogenic in some circumstances and may provoke dangerous allergic reactions. The injection of DNA encoding subunits or modified forms of the target antigens (e.g., insulin B-chain peptide, secreted GAD65 or fusion with IgG-Fc) has improved results, although the mechanisms underlying these effects are not totally elucidated. Of note, none of the early studies reported induction of $\operatorname{Tr}$ cells of a classical phenotype (non-Th2), but more recent studies reveal that this is possible. At least three recently described approaches have produced $\operatorname{Tr}$ cells. One approach involved intranasal delivery of proinsulin II DNA. ${ }^{60}$ These authors induced unusual CD4 $4^{+}$Tr cells, of either CD25 $5^{+}$or CD25 phenotype that did not express Foxp3 and other typical Tr markers. These Tr cells only prevented diabetes when immunization was combined with CD40 ligand blockade. Other authors applied a proapoptotic DNA vaccine to induce Tr cells. ${ }^{61}$ The incorporation of a cDNA coding for the proapoptotic protein BAX into plasmid DNA coding for a secreted form of GAD65 (sGAD55) protected partially against diabetes in NOD mice. Interestingly, this vaccine induced $\mathrm{CD}^{+} \mathrm{CD} 25^{+} \mathrm{Foxp}^{+} \mathrm{Tr}$ cells that mediated cell contact-dependent immunosuppressive activity. These Tr cells appear to arise from CD25peripheral precursor T cells.

In a third approach, we have generated $\operatorname{Tr}$ cells by DNA vaccination by incorporating cDNA encoding a mutated form of B7-1 (B7-1wa) that selectively binds CTLA-4, that is, it has lost the ability to bind CD28. ${ }^{39}$ The negative regulator CTLA-4 is the most studied and possibly the most potent T-cell inhibitory molecule. ${ }^{3,21}$ It is expressed by $\mathrm{T}$ cells after activation and, similar to the positive costimulatory molecule CD28, binds to B7-1 (CD80) and B7-2 (CD86) on the membrane of APCs. It then downregulates T-cell reactivity by mechanisms that

Table 3 Alteration of autoimmune diabetes by DNA vaccination

\begin{tabular}{|c|c|c|c|c|c|}
\hline Diabetes model & Vaccine (cDNA) & Covaccine (cDNA) & Disease severity & Postulated mechanism of protection & Reference \\
\hline TG RIP-LCMV & Ins B & None & $\downarrow^{\mathrm{a}}$ & TH2 bias & 50 \\
\hline \multirow[t]{2}{*}{ TG RIP-B7.1 } & PPIns, PIns, Ins & None & $\uparrow$ & & 51 \\
\hline & GAD65 & None & - & & 51 \\
\hline \multirow{2}{*}{ NOD } & Empty & None & $\downarrow$ & Th2 bias & 88 \\
\hline & HSP60 & None & $\downarrow$ & Th2 bias & 88 \\
\hline NOD/CYP & HSP60 & None & $\downarrow$ & Th2 bias & 89 \\
\hline NOD & Ins B9-23 & None & $\downarrow$ & IFN $\gamma \downarrow$ & 52 \\
\hline NOD & Ins B9-23 & None or IL-4 & $\downarrow$ & Th2 bias & 53 \\
\hline \multirow[t]{2}{*}{ NOD } & InsA-IgG-Fc & None or IL-4 & - & & 54 \\
\hline & InsB-IgG-Fc & None or IL-4 & $\uparrow$ & & 54 \\
\hline \multirow[t]{2}{*}{ NOD } & PPIns & None & - & & 59 \\
\hline & PPIns & B7-1wa (CTLA-4 ligand) & $\downarrow$ & T-cell unresponsivess to insulin & 59 \\
\hline NOD & Ins-GAD & B7-1wa (CTLA-4 ligand) & $\downarrow$ & Tr cells $\left(\right.$ CTLA- $4^{+}$, Foxp $3^{+}$, membrane TGF- $\left.\beta 1^{+}\right)$ & 39 \\
\hline NOD & GAD65 & None & - & & 55 \\
\hline NOD & GAD65 & None & $\downarrow$ & & 56 \\
\hline NOD & rVV-GAD65 & None & $\downarrow$ & Th2 bias & 57 \\
\hline \multirow{2}{*}{ NOD } & GAD65 & None & - & & 58 \\
\hline & spGAD (secreted) & None & $\downarrow$ & IL-10个, TGF- $\beta 1 \uparrow$ & 58 \\
\hline NOD/CYP & sGAD55 (secreted) & None & $\downarrow$ & Th2 bias & 91 \\
\hline \multirow[t]{2}{*}{ NOD } & GAD65-IgG-Fc & None & - & & 54 \\
\hline & GAD65-IgG-Fc & $\mathrm{IL}-4^{+} /-\mathrm{IL}-10$ & $\downarrow$ & Th2 bias & 54,90 \\
\hline NOD & PPIns II (nasal) & None & $\downarrow$ & $\operatorname{Tr}$ cells (non-conventional) & 60 \\
\hline NOD & sGAD55 (secreted) & BAX (proapoptotic) & $\downarrow$ & Tr cells $\left(\right.$ Foxp $\left.^{+}\right)$ & 61 \\
\hline
\end{tabular}

Abbreviations: CYP, cyclophosphamide; GAD65, glutamic acid decarboxylase 65; GAD65-IgG-Fc, GAD65-segment construct fused to an IgGFc segment; HSP60, heat shock protein 60; Ins, insulin; Ins-GAD, preproinsulin-GAD65 fusion protein; LMCV, lymphocytic choriomeningitis virus; PIns, proinsulin; PPIns, preprosinsulin; sGAD55, secreted form of GAD, 55 kDa; spGAD65, secreted GAD65; TG RIP-B7, transgenic mice with islet-restricted expression of B7.1 under the control of the rat insulin promoter (RIP); TG RIP-LCMV, transgenic mice with isletrestricted expression of LMCV nucleoprotein under the control of the rat insulin promoter (RIP); Tr, regulatory T cells; vvGAD65, recombinant vaccinia virus expressing GAD65.

a $\uparrow$, increased; $\downarrow$, decreased; - , unchanged; $+/-$, with or without. 
are not fully elucidated. Of note, CTLA-4 delivers a signal early after T-cell activation that primes the T cells for responsiveness to TGF- $\beta$ and also appears essential for Foxp3 expression and Tr differentiation. ${ }^{11,12,62,63}$ Thus, it appears that CTLA-4, TGF- $\beta$ and Foxp3 are molecules that work together in the generation of induced $\mathrm{Tr}$ cells. Their importance is highlighted by the fact that knockout of any of these three genes in mice results in early death (3 or 4 weeks of age) from multi-organ inflammatory disease (Table 2). ${ }^{3,21}$ CTLA-4 is underexpressed in autoimmune diabetes-prone NOD mice. In humans, some polymorphisms of the gene, which alter CTLA-4 levels or function, increase susceptibility to T1D and other autoimmune diseases. ${ }^{3,21}$

As there is evidence that both insulin and GAD65 are major antigens in T1D, we designed Ins-GAD, consisting of full-length preproinsulin (PPIns) and GAD65, as a composite target antigen that would include many key epitopes. We immunized NOD mice with Ins-GAD and B7-1wa (CTLA-4 ligand), or control vectors, and found that this strongly protected against onset of diabetes. ${ }^{39}$ In a previous study using PPIns, instead of Ins-GAD, we observed less protection. ${ }^{59}$ Adoptive transfer of $\mathrm{T}$ cells from Ins-GAD/B7-1wa-co-vaccinated mice revealed the presence of protective $\mathrm{Tr}$ cells of both $\mathrm{CD} 4{ }^{+} \mathrm{CD} 25^{+}$and $\mathrm{CD} 4^{+} \mathrm{CD} 25^{-}$phenotype. Furthermore, there were significantly increased numbers of $\mathrm{CD} 4^{+} \mathrm{T}$ cells expressing markers of $\operatorname{Tr}$ cells including CTLA-4, Foxp3 and membrane-bound LAP-TGF- $\beta$. All of these molecules have been linked to $\mathrm{Tr}$ function. It should be noted that these vaccination studies were performed with in vivo $\mathrm{EP}$, which we have found to be effective in this setting. In conclusion, DNA co-vaccination with autoantigens and a CTLA-4 ligand induced Tr cells that prevented autoimmunity. This represents a powerful and versatile approach that could find applications in various autoimmune diseases.

\section{Insulin and other molecules delivered by gene therapeutic approaches}

There has been considerable interest in transplanting genetically engineered cells capable of producing insulin for the treatment of insulin-dependent diabetes or, alternatively, in using somatic gene therapy to supply insulin. Unfortunately, efforts to design non-endocrine cells that respond physiologically to glucose have been unsuccessful to date. However, continuous low-level (or basal) production of insulin could be beneficial in T1D or T2D patients, provided hypoglycemia was not induced. We studied in mice a muscle-based gene therapy that required engineering proinsulin for processing by nonendocrine cells. ${ }^{64}$ The maturation process of insulin is dependent on the action of two endopeptidases proprotein convertase (PC). The PC2 and the PC1 or $3(\mathrm{PC} 1 / 3)$ are specifically expressed in the beta cells of the islets of Langerhans and some neuroendocrine cells. In nonendocrine cells, similar processing can be accomplished by adding furin cleavage sites, which were added to our construct.

The plasmid-mediated therapy was given to streptozotocin (STZ)-induced diabetic mice. ${ }^{64}$ Two plasmids were co-delivered, one encoding a furin-cleavable insulin and the other furin. Insulin was further mutated to increase its activity, and in vivo EP was used to enhance gene transfer. With this approach, we were able to demonstrate processing of proinsulin to the mature form and release of sufficient active insulin to prevent hyperglycemia. Our therapy resulted in protection against hyperglycemia and a marked increase in plasma levels of proinsulin, mature insulin and free C-peptide. Nevertheless, the ultimate goal of regulated insulin production will be very difficult to achieve. An alternative approach for the future, however, might be to apply gene therapy to promote islet-cell proliferation or regeneration, and/or to protect islet cells from injury or apoptosis, as discussed below.

\section{GLP-1 or GLP-1-Fc gene therapy}

GLP-1 is a major physiological incretin (stimulates insulin production after oral glucose intake), which plays numerous important roles in modulating blood glucose homeostasis. Because of its potent biological functions, including stimulation of glucose-dependent insulin secretion, inhibition of glucagon secretion, delay of gastric emptying, $\beta$-cell antiapoptotic effect and enhancement of islet beta-cell mass, GLP-1 has been proposed for the treatment of patients with T2D. However, major obstacles for using native GLP-1 as therapeutic agent are that it must be delivered by a parenteral route and has a short circulating $t_{1 / 2}(<2 \mathrm{~min})$. This results from its small size (3.3. kDa) allowing rapid renal clearance, as well as enzymatic digestion by dipeptidyl peptidase IV (DPP-IV) in the plasma. One strategy has involved using a longer acting, DPP-IVresistant agonist of the GLP-1 receptor, exendin-4. In another attempt to develop a strategy to prolong the physiological $t_{1 / 2}$ and enhance the potency of GLP-1, a fusion gene encoding the active human GLP-1 and mouse IgG1 heavy-chain constant regions (GLP-1-Fc) was generated. ${ }^{65}$ This construct was inserted into a plasmid encoding an $\operatorname{Ig} \kappa$ leader peptide to generate a secretable GLP-1-Fc fusion protein. We also produced constructs where GLP-1 was mutated such that it resisted degradation by DPP-IV. In vitro studies employing purified GLP-1-Fc indicate that the fusion protein is functional and elevates cAMP levels in insulin-secreting INS-1 cells. In addition, it stimulates insulin secretion in a glucose concentration-dependent manner. Intramuscular gene transfer of a GLP-1-Fc plasmid in T2D $\mathrm{db} / \mathrm{db}$ mice, enhanced by EP, demonstrated that expression of the GLP-1/Fc peptide normalizes glucose tolerance by enhancing insulin secretion and suppressing glucagon release. The therapeutic effects were apparent several months after the administration of DNA.65

Moreover, in STZ-induced diabetes, GLP-1-Fc gene transfer protected beta islet cells against the toxic effects of this drug. ${ }^{66}$ Therapy resulted in a marked improvement in islet beta-cell mass, ameliorated plasma insulin levels and protected against hyperglycemia. The increase in beta-cell mass probably resulted from a combination of improved beta-cell survival (anti-apoptotic effect), and islet-cell regeneration. Recently, we also delivered our GLP-1-Fc plasmid vector to a small number of alloxantreated pigs. Alloxan induced moderate hyperglycemia, and treated pigs had circulating GLP-1-FC protein and improved blood glucose levels (unpublished observa- 
tions). In this case, the vector was injected i.m. and gene transfer was enhanced by constant-current electroporation with the ADViSYS electrokinetic device (EKD). Gene therapy, based on delivery of a bivalent GLP-1/FC fusion protein, is a novel approach for the treatment of diabetes. A major advantage, unlike insulin gene therapy, is that the level of GLP-1 does not have to be closely controlled and does not need to be regulated by a glucose-sensitive promoter to exert its effects.

\section{Leptin gene therapy in models of obesity and diabetes}

There has been considerable interest in developing leptin gene therapy for the control of obesity. This can be done with viral vectors, but it was also demonstrated to be possible by transfer of the leptin gene in muscle using EP-enhanced methods. ${ }^{4}$ In mice treated by EP, elevated serum leptin concentrations up to $90 \mathrm{ng} / \mathrm{ml}$ have been recorded ( $>200$-fold increase over control mice). Indeed, electrogene transfer resulted in hyperleptinemia, decreased food intake and lower body weight. Furthermore, the production of insulin was lowered in treated mice, but their blood glucose remained normal. Conversely, to investigate whether in vivo gene transfer causes leptinantagonistic effects on food intake, animal body weight and fat tissue weight, an R128Q mutated-leptin gene was used, ${ }^{67}$ and EP was compared to the hydrodynamic method of gene delivery. Mutated-leptin gene transfer by EP caused significant increases in body weight at 5 days and thereafter (5.4\% increase relative to control). This resulted in significantly increases in tissue weight of epididymal white fat and neuropeptide Y mRNA expression in the hypothalamus compared with those of the control group up to 3 weeks after gene transfer, suggesting that mutated-leptin gene transfer successfully produced leptin-antagonistic effects by modulating the central regulator of energy homeostasis. Also, the extent of leptin-antagonistic effects by EP was much higher than hydrodynamics-based gene delivery, with at least single gene transfer.

\section{Gene therapy to promote wound healing}

A major application of EP-based gene therapy might be in the treatment of cutaneous wounds that occur in many clinical settings and are particularly difficult to treat in diabetic patients. The cost of treating poorly healing foot wounds in the United States has been estimated at over $\$ 1$ billion per year. Wound-localized electrogene transfer of DNA encoding either keratinocyte growth factor or TGF- $\beta^{68,69}$ was beneficial in diabetic mice. Notably, TGF- $\beta$ and EP appeared to act synergistically to promote healing. Because EP has been applied in patients for other purposes, it could probably be applied to promote wound healing, and this will undoubtedly be an area of future clinical investigation.

\section{Gene therapy with other hormone- encoding plasmids}

We have tested a GHRH-expressing plasmid expressed in skeletal muscle following i.m. injection enhanced by
$\mathrm{EP}^{4,9,70,71}$ The GHRH is released in the systemic circulation and ectopically stimulates the animal's pituitary to produce and release growth hormone (GH). GH induces other tissues to produce insulin-like growth factor-I (IGFI). Young pigs directly injected with as little as $0.1 \mathrm{mg}$ of a GHRH-expressing plasmid had significantly greater weight gain than controls, a significant increase in lean body mass and a decrease in fat mass. The offspring of gilts (250-400 kg) injected i.m. and electroporated at day 85 of gestation with $1-5 \mathrm{mg}$ of a GHRH-expressing plasmid have optimized growth characteristics owing to both improved intrauterine weight gain and enhanced maternal lactation performance. ${ }^{4,70,71}$ Thus, the piglets from treated gilts were larger at birth and weaning compared with controls and exhibited a significantly reduced morbidity and mortality. An important finding is that the analysis of more than 300 treated animals revealed that expression was maintained for at least 1 year, and the beneficial effects on the offspring occurred for three consecutive pregnancies in the treated animals after one single plasmid administration. In all these experiments, the constant-current EKD has been used. One of the advantages of the constant-current EKD is that an impedance test to assess the individual muscle resistance is automatically performed by the EKD electrodes before the plasmid injection and electroporation could occur, to avoid plasmid injection in a suboptimal location (blood vessel, fat tissue and fascia). Furthermore, constant-current EP, unlike the more common constant-voltage methods, protects against overheating and damage to tissues that are due to a rapid reduction in electrical resistance as multiple electical pulses are applied. ${ }^{4}$ A five-electrode array was used in all experiments, with the plasmid administered through a syringe introduced in the muscle area delineated by the electrodes. ${ }^{72} \mathrm{EP}$ conditions in these very large mammals were generally: electric field intensity of $0.5-0.6 \mathrm{~A}, 3$ pulses, $52 \mathrm{~ms} /$ pulse. The positive results obtained with plasmid-based GHRH in production animals prove that by combining adequate plasmid design with the constant-current EP method, one can obtain physiologic levels of a transgene product even in a $500 \mathrm{~kg}$ animal, giving hope that soon this and other applications may be translated to a number of human applications.

\section{Gene therapy of ischemic disease}

Cardiovascular disease is the leading cause of premature death and disability among diabetic patients. Critical limb ischemia (CLI) is a disease manifested by sharply diminished blood flow to the legs, and the most common cause of non-traumatic amputation in diabetes. This condition is responsible for $70 \%$ of the lower limb amputations. ${ }^{73}$ Although a combination of neuropathy, obstructive macrovascular disease and/or microvascular changes is usually pivotal in the development of the diabetic foot, the contribution of microvascular occlusions is predominant in the diabetic subgroup with CLI and is not accessible for surgical revascularization. ${ }^{74,75}$ The median survival of patients with CLI is approximately 3 years. ${ }^{76}$ The quality of life during this period is limited. ${ }^{77}$ Despite advances in revascularization techniques, limb salvage and relief of pain cannot be achieved 
Table 4 Clinical trials using plasmids ${ }^{\mathrm{a}}$ (2004-present)

\begin{tabular}{|c|c|c|c|c|c|c|}
\hline Trial name & $N R$ & Transgene & Phase & Sponsor & Indication & Clinical sites \\
\hline $\begin{array}{l}\text { Study of HGF via plasmid vector to improve } \\
\text { perfusion in critical limb ischemia patients with } \\
\text { peripheral ischemic ulcers }\end{array}$ & 48 & HGF & II & AnGes & $\begin{array}{l}\text { CLI with peripheral } \\
\text { ischemic ulcers }\end{array}$ & USA -8 sites \\
\hline $\begin{array}{l}\text { Phase II, randomized, double-blind, placebo- } \\
\text { controlled, parallel group, efficacy and safety } \\
\text { study of NV1FGF in patients with severe } \\
\text { peripheral artery occlusive disease }\end{array}$ & 125 & $\begin{array}{l}\text { pCOR plasmid } \\
\text { constructed by } \\
\text { inserting the gene } \\
\text { coding for the FGF } \\
\text { (NV1FGF) }\end{array}$ & II & Sanofi-Aventis & $\begin{array}{l}\text { Peripheral arterial } \\
\text { disease }\end{array}$ & $\begin{array}{l}\text { Belgium, France, } \\
\text { Germany, Italy, } \\
\text { Switzerland and } \\
\text { United Kingdom }\end{array}$ \\
\hline $\begin{array}{l}\text { Modulation of VEGF using an engineered zinc- } \\
\text { finger transcription factor to treat lower limb } \\
\text { intermittent claudication }\end{array}$ & 36 & $\begin{array}{l}\text { EW-A-401 DNA } \\
\text { plasmid vector }\end{array}$ & I & $\begin{array}{l}\text { National Heart, } \\
\text { Lung, and Blood } \\
\text { Institute (NHLBI) }\end{array}$ & $\begin{array}{l}\text { Lower limb } \\
\text { intermittent } \\
\text { claudication }\end{array}$ & USA - 1 site \\
\hline $\begin{array}{l}\text { A phase II double-blind, randomized, placebo- } \\
\text { controlled study to assess the safety and } \\
\text { efficacy of AMG0001 to improve perfusion in } \\
\text { critical leg ischemia }\end{array}$ & 100 & $\begin{array}{l}\text { HGF transferred via } \\
\text { plasmid vector } \\
\text { (AMG0001) }\end{array}$ & II & AnGes & CLI & USA - 16 sites \\
\hline $\begin{array}{l}\text { Phase II multicenter, double-blind, placebo- } \\
\text { controlled, trial of VLTS- } 589 \text { in subjects with } \\
\text { intermittent claudication secondary to } \\
\text { peripheral arterial disease }\end{array}$ & 100 & $\begin{array}{l}\text { Plasmid based gene } \\
\text { transfer product- } \\
\text { VLTS- } 589\end{array}$ & II & Valentis & $\begin{array}{l}\text { Intermittent } \\
\text { claudication } \\
\text { peripheral vascular } \\
\text { disease }\end{array}$ & USA - 18 sites \\
\hline $\begin{array}{l}\text { The effect of mobilized stem cell by G-CSF and } \\
\text { VEGF gene therapy in patients with stable } \\
\text { severe angina pectoris }\end{array}$ & 48 & $\begin{array}{l}\text { VEGF-A165 } \\
\text { plasmid }\end{array}$ & I and II & $\begin{array}{l}\text { Rigshospitalet, } \\
\text { Denmark }\end{array}$ & $\begin{array}{l}\text { Ischemic heart } \\
\text { disease }\end{array}$ & Denmark \\
\hline $\begin{array}{l}\text { To find the best dose of pVGI.1 (VEGF2) to } \\
\text { benefit angina patients when given with an } \\
\text { experimental injection catheter }\end{array}$ & 404 & $\begin{array}{l}\text { Recombinant } \\
\text { plasmid DNA - } \\
\text { pVGI.1 (VEGF2) }\end{array}$ & II & Corautus Genetics & Angina pectoris & USA - 22 sites \\
\hline
\end{tabular}

aCompleted and ongoing clinical trials listed on the Food and Drug Administration (FDA) web site.

Abbreviations: .CLI, critical limb ischemia; HGF, hepatocyte growth factor; VEGF, vascular endothelial growth factor. 
in many diabetic patients with diffuse peripheral vascular disease.

There are several studies of plasmid-based gene therapy of ischemic disease (Table 4). A very recent report $^{78}$ presented the results of a human clinical trial performed in The Netherlands, with the primary objective to determine the effect of i.m. administration of phVEGF165 (vascular endothelial growth factor (VEGF) gene-carrying plasmid) on CLI compared with placebo $(0.9 \% \mathrm{NaCl})$. The double-blind, placebocontrolled study was performed in 54 adult diabetic patients with CLI. The primary end point was the amputation rate at 100 days. Secondary end points were a $15 \%$ increase in pressure indices (ankle-to-brachial index and toe-to-brachial index), clinical improvement (skin pain and 'quality of life' scores) and safety. In patients $(n=27)$ treated with placebo vs phVEGF165-treated patients ( $n=27)$, the following results were found: 6 amputations vs three $(P=$ not significant [NS]); hemodynamic improvement in one vs seven $(P=0.05)$ improvement in skin ulcers, zero vs seven $(P=0.01)$; decrease in pain, two vs five $(P=\mathrm{NS})$ and overall, three vs 14 responding patients $(P=0.003)$. Many of the patients in treated or placebo groups had other associated cardiovascular pathology, such as hypertension (18 vs 15), hypercholesterolemia (eight vs nine) and angina pectoris (nine vs 12). No substantial, grade 3 or 4 adverse effects were seen in these patients. The authors conclude that this small, randomized gene therapy study failed to meet the primary objective of significant amputation reduction. However, significant and meaningful improvement was found in patients treated with a VEGF165-containing plasmid.

\section{Non-viral gene transfer in humans}

Most of the human studies have been in the area of DNA vaccination, although EP was not applied (for detailed information regarding the clinical trials, see www. clinicaltrials.gov). Notably, immune responses can be generated against malaria antigens by i.m. DNA vaccination and recent studies point to heterologous plasmid/ virus prime-boost strategies as an effective method of generating immunity. Antigen-reactive T cells are readily induced, but antibody responses are usually of low magnitude. Preclinical studies suggest that this limitation might be addressed by EP. ${ }^{4}$ Non-viral DNA transfer into humans has had a remarkable safety profile and thus is attracting more attention.

A recent review of all human gene therapy clinical trials worldwide from 1999 to 2005 showed that approximately $17 \%$ involved plasmids $(n=192$ out of a total 1134 trials) (review complied in the Journal of Gene Medicine, 2006 and published on-line: http://www. wiley.co.uk/genetherapy/clinical). A significant number of trials using plasmids (phase I, I/II or phase II) have been completed in the last few years or are still ongoing (http://www.clinicaltrials.gov), some targeting peripheral ischemic disease or angina (see Table 4). Other phase I trials, assessing the safety profiles of the plasmids, in particular using VEGF-expressing plasmids, have been completed. ${ }^{79}$ In summary, considerable progress has been reported in the field, even if some trials have been less successful in attaining their primary end
Table 5 Applications of EP-enhanced gene therapy ${ }^{\mathrm{a}}$

- Autoimmune diseases (cytokines and cytokine receptors/anticytokines and DNA vaccination)

- Cancer therapy (intra-tumoural or systemic delivery of vectors encoding cytokines, suicide genes, etc.)

- Endocrine therapy (GHRH, leptin, insulin, GLP-1, other)

- Hematopoietic factors (e.g., erythropoietin, GM-CSF, FLT3 ligand)

- Hemophilia therapy (Factor VIII or IX)

- Antibodies

- DNA vaccination against infectious agents or cancer antigens (boosted greatly by EP)

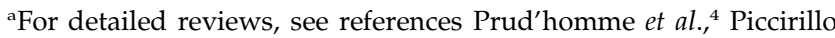
et al., ${ }^{8}$ Ratanamart and Shaw, ${ }^{11}$ Prud'homme, ${ }^{41}$ Stevenson et al., ${ }^{42}$ and van Drunen Littel-van den Hurk et al. ${ }^{43}$

points. Overall, these studies produced some encouraging results in preclinical studies and clinical trials, encouraged research towards better plasmid design and delivery methods and established the basis of a successful gene therapeutic approach for the treatment of diabetes and other diseases and their complications in the not too far future.

\section{Future prospects}

Gene therapy using plasmid-based gene transfer and EP can be effectively applied in both small and large animals and has many potential applications (Table 5). This approach has been successfully employed in preclinical autoimmune and/or inflammatory diseases to deliver cytokines, anti-inflammatory agents or DNA vaccines. Notably, it has been found to be highly effective in boosting DNA vaccination against a wide variety of antigens of relevance to infection, cancer or autoimmunity. One of the most promising applications is in the systemic delivery of protein drugs, such as endocrine hormones, hematopoietic factors, antibodies, enzymes and others. As we have outlined, several of these therapeutic approaches are relevant to the prevention or treatment of diabetes and its complications.

EP-assisted methods are not limited to these applications. Indeed, the use of non-viral nucleic acids in experimental therapy is constantly expanding. The most remarkable new development, however, is the introduction of small inhibitory RNA (siRNA)-based therapeutic agents. Synthetic or vector-delivered siRNAs are powerful new tools for gene silencing and their potential therapeutic applications are numerous. However, targeting the in vivo delivery of these molecules to a specific tissue is difficult, and EP-enhanced non-viral methods of nucleic acid transfer have advantages in terms of simplicity, effectiveness and safety.

\section{Acknowledgements}

Our studies were funded by the Krembil Foundation (Toronto, Canada), the Juvenile Diabetes Research Foundation International, the Canadian Diabetes Association, the National Cancer Institute of Canada, the Canadian Institutes of Health Research, St Michael's 
Hospital Foundation (Toronto, Canada) and the Ontario Cancer Research Network.

\section{References}

1 Frederickson RM, Carter BJ, Pilaro AM. Nonclinical toxicology in support of licensure of gene therapies. Mol Ther 2003; 8: 8-10.

2 Wolff JA, Malone RW, Williams P, Chong W, Acsadi G, Jani A et al. Direct gene transfer into mouse muscle in vivo. Science 1990; 247 (4949 Part 1): 1465-1468.

3 Wolff JA, Ludtke JJ, Acsadi G, Williams P, Jani A. Long-term persistence of plasmid DNA and foreign gene expression in mouse muscle. Hum Mol Genet 1992; 1: 363-369.

4 Prud'homme GJ, Glinka Y, Khan AS, Draghia-Akli R. Electroporation-enhanced nonviral gene transfer for the prevention or treatment of immunological, endocrine and neoplastic diseases. Curr Gene Ther 2006; 6: 243-273.

5 Mir LM, Bureau MF, Gehl J, Rangara R, Rouy D, Caillaud JM et al. High-efficiency gene transfer into skeletal muscle mediated by electric pulses. Proc Natl Acad Sci USA 1999; 96: 4262-4267.

6 Li X, Eastman EM, Schwartz RJ, Draghia-Akli R. Synthetic muscle promoters: activities exceeding naturally occurring regulatory sequences. Nat Biotechnol 1999; 17: 241-245.

7 Prud'homme GJ, Lawson BR, Chang Y, Theofilopoulos AN. Immunotherapeutic gene transfer into muscle. Trends Immunol 2001; 22: 149-155.

8 Piccirillo CA, Theofilopoulos AN, Prud'homme G. Immunogene therapy with non-viral vectors. In: Prud'homme G (ed). Gene Therapy of Autoimmune Diseases. Landes Publishers and Kluwer Academic/Plenum Publishers: New York, 2005, pp 43-70.

9 Khan AS, Pope MA, Draghia-Akli R. Highly efficient constantcurrent electroporation increases in vivo plasmid expression. DNA Cell Biol 2005; 24: 810-818.

10 Andre F, Mir LM. DNA electrotransfer: its principles and an updated review of its therapeutic applications. Gene Therapy 2004; 11 (Suppl 1): S33-S42.

11 Ratanamart J, Shaw JA. Plasmid-mediated muscle-targeted gene therapy for circulating therapeutic protein replacement: a tale of the tortoise and the hare? Curr Gene Ther 2006; 6: 93-110.

12 Heller LC, Heller R. In vivo electroporation for gene therapy. Hum Gene Ther 2006; 17: 890-897.

13 Dowty ME, Williams P, Zhang G, Hagstrom JE, Wolff JA. Plasmid DNA entry into postmitotic nuclei of primary rat myotubes. Proc Natl Acad Sci USA 1995; 92: 4572-4576.

14 Lechardeur D, Lukacs GL. Nucleocytoplasmic transport of plasmid DNA: a perilous journey from the cytoplasm to the nucleus. Hum Gene Ther 2006; 17: 882-889.

15 Dean DA. Nonviral gene transfer to skeletal, smooth, and cardiac muscle in living animals. Am J Physiol Cell Physiol 2005; 289: C233-C245.

16 Manam S, Ledwith BJ, Barnum AB, Troilo PJ, Pauley CJ, Harper LB et al. Plasmid DNA vaccines: tissue distribution and effects of DNA sequence, adjuvants and delivery method on integration into host DNA. Intervirology 2000; 43: 273-281.

17 Ledwith BJ, Manam S, Troilo PJ, Barnum AB, Pauley CJ, Griffiths TG et al. Plasmid DNA vaccines: investigation of integration into host cellular DNA following intramuscular injection in mice. Intervirology 2000; 43: 258-272.

18 Wang Z, Troilo PJ, Wang X, Griffiths TG, Pacchione SJ, Barnum $\mathrm{AB}$ et al. Detection of integration of plasmid DNA into host genomic DNA following intramuscular injection and electroporation. Gene Therapy 2004; 11: 711-721.

19 Klinman DM. Immunotherapeutic uses of CpG oligodeoxynucleotides. Nat Rev Immunol 2004; 4: 249-258.

20 Krieg AM. CpG motifs in bacterial DNA and their immune effects. Annu Rev Immunol 2002; 20: 709-760.
21 Prud'homme GJ. Altering immune tolerance therapeutically: the power of negative thinking. J Leukoc Biol 2004; 75: 586-599.

22 Anderson MS, Bluestone JA. The NOD mouse: a model of immune dysregulation. Annu Rev Immunol 2005; 23: 447-485.

23 Rizzi M, Ferrera F, Filaci G, Indiveri F. Disruption of immunological tolerance: role of AIRE gene in autoimmunity. Autoimmun Rev 2006; 5: 145-147.

24 Villasenor J, Benoist C, Mathis D. AIRE and APECED: molecular insights into an autoimmune disease. Immunol Rev 2005; 204: 156-164.

25 Piccirillo CA, Shevach EM. Naturally-occurring CD4+CD25+ immunoregulatory $\mathrm{T}$ cells: central players in the arena of peripheral tolerance. Semin Immunol 2004; 16: 81-88.

26 Sakaguchi S. Naturally arising Foxp3-expressing CD25+CD4+ regulatory $\mathrm{T}$ cells in immunological tolerance to self and nonself. Nat Immunol 2005; 6: 345-352.

27 Taams LS, Palmer DB, Akbar AN, Robinson DS, Brown Z, Hawrylowicz CM. Regulatory $\mathrm{T}$ cells in human disease and their potential for therapeutic manipulation. Immunology 2006; 118: $1-9$.

28 Ziegler SF. FOXP3: of mice and men. Annu Rev Immunol 2006; 24: 209-226.

29 Veldman C, Nagel A, Hertl M. Type I regulatory T cells in autoimmunity and inflammatory diseases. Int Arch Allergy Immunol 2006; 140: 174-183.

30 Nieves DS, Phipps RP, Pollock SJ, Ochs HD, Zhu Q, Scott GA et al. Dermatologic and immunologic findings in the immune dysregulation, polyendocrinopathy, enteropathy, X-linked syndrome. Arch Dermatol 2004; 140: 466-472.

31 Gambineri E, Torgerson TR, Ochs HD. Immune dysregulation, polyendocrinopathy, enteropathy, and X-linked inheritance (IPEX), a syndrome of systemic autoimmunity caused by mutations of FOXP3, a critical regulator of T-cell homeostasis. Curr Opin Rheumatol 2003; 15: 430-435.

32 Prud'homme GJ. Prevention of autoimmune diabetes by DNA vaccination. Expert Rev Vaccines 2003; 2: 533-540.

33 Yang Y, Santamaria P. Lessons on autoimmune diabetes from animal models. Clin Sci (London) 2006; 110: 627-639.

34 Prud'homme GJ, Chang Y. Prevention of autoimmune diabetes by intramuscular gene therapy with a nonviral vector encoding an interferon-gamma receptor/IgG1 fusion protein. Gene Therapy 1999; 6: 771-777.

35 Chang Y, Prud'homme GJ. Intramuscular administration of expression plasmids encoding interferon-gamma receptor/IgG1 or IL-4/IgG1 chimeric proteins protects from autoimmunity. J Gene Med 1999; 1: 415-423.

36 Lawson BR, Prud'homme GJ, Chang Y, Gardner HA, Kuan J, Kono DH et al. Treatment of murine lupus with cDNA encoding IFN-gammaR/Fc. J Clin Invest 2000; 106: 207-215.

37 Gomez-Reino JJ, Carmona L, Valverde VR, Mola EM, Montero MD. Treatment of rheumatoid arthritis with tumor necrosis factor inhibitors may predispose to significant increase in tuberculosis risk: a multicenter active-surveillance report. Arthritis Rheum 2003; 48: 2122-2127.

38 Slifman NR, Gershon SK, Lee JH, Edwards ET, Braun MM. Listeria monocytogenes infection as a complication of treatment with tumor necrosis factor alpha-neutralizing agents. Arthritis Rheum 2003; 48: 319-324.

39 Glinka Y, Chang Y, Prud'homme GJ. Protective regulatory T cell generation in autoimmune diabetes by DNA covaccination with islet antigens and a selective ctla-4 ligand. Mol Ther 2006; 14: 578-587.

40 Prud'homme G, Glinka Y, Chang Y, Li X. DNA vaccination against autoimmune diseases. In: Prud'homme G (ed). Gene Therapy of Autoimmune Diseases. Landes Publishers and Kluwe Academic/Plenum Publishers: New York, 2005, pp 112-136.

41 Prud'homme GJ. DNA vaccination against tumors. J Gene Med 2005; 7: 3-17. 
42 Stevenson FK, Ottensmeier CH, Johnson P, Zhu D, Buchan SL, McCann KJ et al. DNA vaccines to attack cancer. Proc Natl Acad Sci USA 2004; 101 (Suppl 2): 14646-14652.

43 van Drunen Littel-van den Hurk S, Babiuk SL, Babiuk LA. Strategies for improved formulation and delivery of DNA vaccines to veterinary target species. Immunol Rev 2004; 199: 113-125.

44 Kent SC, Chen Y, Bregoli L, Clemmings SM, Kenyon NS, Ricordi $\mathrm{C}$ et al. Expanded T cells from pancreatic lymph nodes of type 1 diabetic subjects recognize an insulin epitope. Nature 2005; 435: 224-228.

45 Nakayama M, Abiru N, Moriyama H, Babaya N, Liu E, Miao D et al. Prime role for an insulin epitope in the development of type 1 diabetes in NOD mice. Nature 2005; 435: 220-223.

46 Karges W, Pechhold K, Al DS, Riegger I, Rief M, Wissmann A et al. Induction of autoimmune diabetes through insulin (but not GAD65) DNA vaccination in nonobese diabetic and in RIP-B7.1 mice. Diabetes 2002; 51: 3237-3244.

47 Devendra D, Paronen J, Moriyama H, Miao D, Eisenbarth GS, Liu E. Differential immune response to B:9-23 insulin 1 and insulin 2 peptides in animal models of type 1 diabetes. J Autoimmun 2004; 23: 17-26.

48 Chen W, Bergerot I, Elliott JF, Harrison LC, Abiru N, Eisenbarth GS et al. Evidence that a peptide spanning the B-C junction of proinsulin is an early autoantigen epitope in the pathogenesis of type 1 diabetes. J Immunol 2001; 167: 4926-4935.

49 Liu E, Moriyama H, Abiru N, Miao D, Yu L, Taylor RM et al. Anti-peptide autoantibodies and fatal anaphylaxis in NOD mice in response to insulin self-peptides B:9-23 and B:13-23. J Clin Invest 2002; 110: 1021-1027.

50 Coon B, An LL, Whitton JL, von Herrath MG. DNA immunization to prevent autoimmune diabetes. J Clin Invest 1999; 104: 189-194.

51 Karges W, Pechhold K, Al DS, Riegger I, Rief M, Wissmann A et al. Induction of autoimmune diabetes through insulin (but not GAD65) DNA vaccination in nonobese diabetic and in RIP-B7.1 mice. Diabetes 2002; 51: 3237-3244.

52 Urbanek-Ruiz I, Ruiz PJ, Paragas V, Garren H, Steinman L, Fathman CG. Immunization with DNA encoding an immunodominant peptide of insulin prevents diabetes in NOD mice. Clin Immunol 2001; 100: 164-171.

53 Bot A, Smith D, Bot S, Hughes A, Wolfe T, Wang L et al. Plasmid vaccination with insulin $B$ chain prevents autoimmune diabetes in nonobese diabetic mice. J Immunol 2001; 167: 2950-2955.

54 Weaver Jr DJ, Liu B, Tisch R. Plasmid DNAs encoding insulin and glutamic acid decarboxylase 65 have distinct effects on the progression of autoimmune diabetes in nonobese diabetic mice. J Immunol 2001; 167: 586-592.

55 Wiest-Ladenburger U, Fortnagel A, Richter W, Reimann J, Boehm BO. DNA vaccination with glutamic acid decarboxylase (GAD) generates a strong humoral immune response in BALB/ c, C57BL/6, and in diabetes-prone NOD mice. Horm Metab Res 1998; 30: 605-609.

56 Balasa B, Boehm BO, Fortnagel A, Karges W, Van GK, Jung N et al. Vaccination with glutamic acid decarboxylase plasmid DNA protects mice from spontaneous autoimmune diabetes and B7/CD28 costimulation circumvents that protection. Clin Immunol 2001; 99: 241-252.

57 Jun HS, Chung YH, Han J, Kim A, Yoo SS, Sherwin RS et al. Prevention of autoimmune diabetes by immunogene therapy using recombinant vaccinia virus expressing glutamic acid decarboxylase. Diabetologia 2002; 45: 668-676.

58 Glinka Y, De PR, Croze F, Prud'homme GJ. Regulatory cytokine production stimulated by DNA vaccination against an altered form of glutamic acid decarboxylase 65 in nonobese diabetic mice. J Mol Med 2003; 81: 175-184.

59 Prud'homme GJ, Chang Y, Li X. Immunoinhibitory DNA vaccine protects against autoimmune diabetes through cDNA encoding a selective CTLA-4 (CD152) ligand. Hum Gene Ther 2002; 13: 395-406.

60 Every AL, Kramer DR, Mannering SI, Lew AM, Harrison LC. Intranasal vaccination with proinsulin DNA induces regulatory CD4+ T cells that prevent experimental autoimmune diabetes. J Immunol 2006; 176: 4608-4615.

$61 \mathrm{Li} \mathrm{A}$, Ojogho O, Franco E, Baron P, Iwaki Y, Escher A. Pro-apoptotic DNA vaccination ameliorates new onset of autoimmune diabetes in NOD mice and induces foxp3+ regulatory T cells in vitro. Vaccine 2006; 24: 5036-5046.

62 Zheng SG, Wang JH, Stohl W, Kim KS, Gray JD, Horwitz DA. TGF-beta requires CTLA-4 early after $\mathrm{T}$ cell activation to induce FoxP3 and generate adaptive $\mathrm{CD} 4+\mathrm{CD} 25+$ regulatory cells. J Immunol 2006; 176: 3321-3329.

63 Wohlfert EA, Gorelik L, Mittler R, Flavell RA, Clark RB. Cutting edge: deficiency in the E3 ubiquitin ligase Cbl-b results in a multifunctional defect in T cell TGF-beta sensitivity in vitro and in vivo. J Immunol 2006; 176: 1316-1320.

64 Croze F, Prud'homme GJ. Gene therapy of streptozotocininduced diabetes by intramuscular delivery of modified preproinsulin genes. J Gene Med 2003; 5: 425-437.

65 Kumar M, Hunag Y, Glinka Y, Prud'homme GJ, Wang Q. Gene therapy of diabetes using a novel GLP-1/IgG1-Fc fusion construct normalizes glucose levels in $\mathrm{db} / \mathrm{db}$ mice. Gene Therapy 2006 Aug 31 (Epub ahead of print).

66 Soltani N, Kumar M, Glinka Y, Prud'homme G, Wang Q. In vivo expression of GLP-1/IgG-Fc fusion protein enhances beta-cell mass and protects against streptozocin-induced diabetes. Gene Therapy (in press).

67 Xiang L, Murai A, Muramatsu T. Mutated-leptin gene transfer induces increases in body weight by electroporation and hydrodynamics-based gene delivery in mice. Int $\mathrm{J} \mathrm{Mol} \mathrm{Med}$ 2005; 16: 1015-1020.

68 Marti G, Ferguson M, Wang J, Byrnes C, Dieb R, Qaiser R et al. Electroporative transfection with KGF-1 DNA improves wound healing in a diabetic mouse model. Gene Therapy 2004; 11: 1780-1785.

69 Lee PY, Chesnoy S, Huang L. Electroporatic delivery of TGF-beta1 gene works synergistically with electric therapy to enhance diabetic wound healing in $\mathrm{db} / \mathrm{db}$ mice. J Invest Dermatol 2004; 123: 791-798.

70 Khan AS, Brown PA, Draghia-Akli R. Plasmid-based Growth Hormone Supplementation and its Applications. Curr Opin Mol Ther 2005; 7: 306-316.

71 Draghia-Akli R, Fiorotto ML. A new plasmid-mediated approach to supplement somatotropin production in pigs. J Anim Sci 2004; 82 (13 (E Suppl.)): E264-E269.

72 Hebel HL, Attra HE, Khan AS, Draghia-Akli R. Successful parallel development and integration of a plasmid-based biologic, container/closure system and electrokinetic delivery device. Vaccine 2006; 24: 4607-4614.

73 Eskelinen E, Lepantalo M, Hietala EM, Sell H, Kauppila L, Maenpaa I et al. Lower limb amputations in Southern Finland in 2000 and trends up to 2001. Eur J Vasc Endovasc Surg 2004; 27: 193-200.

74 da Silva AF, Desgranges P, Holdsworth J, Harris PL, McCollum $\mathrm{P}$, Jones SM et al. The management and outcome of critical limb ischaemia in diabetic patients: results of a national survey. Audit committee of the vascular surgical society of Great Britain and Ireland. Diabet Med 1996; 13: 726-728.

75 Holstein P, Ellitsgaard N, Olsen BB, Ellitsgaard V. Decreasing incidence of major amputations in people with diabetes. Diabetologia 2000; 43: 844-847.

76 Cheng SW, Ting AC, Lau H, Wong J. Survival in patients with chronic lower extremity ischemia: a risk factor analysis. Ann Vasc Surg 2000; 14: 158-165.

77 Albers M, Fratezi AC, De LN. Assessment of quality of life of patients with severe ischemia as a result of infrainguinal arterial occlusive disease. J Vasc Surg 1992; 16: 54-59. 
78 Kusumanto YH, van WV, Mulder NH, Smit AJ, van den Dungen JJ, Hooymans JM et al. Treatment with intramuscular vascular endothelial growth factor gene compared with placebo for patients with diabetes mellitus and critical limb ischemia: a double-blind randomized trial. Hum Gene Ther 2006; 17: 683-691.

79 Baumgartner I, Pieczek A, Manor O, Blair R, Kearney M, Walsh K et al. Constitutive expression of phVEGF165 after intramuscular gene transfer promotes collateral vessel development in patients with critical limb ischemia. Circulation 1998; 97: 1114-1123.

80 Aihara H, Miyazaki J. Gene transfer into muscle by electroporation in vivo. Nat Biotechnol 1998; 16: 867-870.

81 Kreiss P, Bettan M, Crouzet J, Scherman D. Erythropoietin secretion and physiological effect in mouse after intramuscular plasmid DNA electrotransfer. J Gene Med 1999; 1: 245-250.

82 Hartikka J, Sukhu L, Buchner C, Hazard D, Bozoukova V, Margalith $\mathrm{M}$ et al. Electroporation-facilitated delivery of plasmid DNA in skeletal muscle: plasmid dependence of muscle damage and effect of poloxamer 188. Mol Ther 2001; 4: 407-415.

83 Thanaketpaisarn O, Nishikawa M, Yamashita F, Hashida M. Tissue-specific characteristics of in vivo electric gene: transfer by tissue and intravenous injection of plasmid DNA. Pharm Res 2005; 22: 883-891.

84 Rizzuto G, Cappelletti M, Mennuni C, Wiznerowicz M, DeMartis A, Maione D et al. Gene electrotransfer results in a high-level transduction of rat skeletal muscle and corrects anemia of renal failure. Hum Gene Ther 2000; 11: 1891-1900.
85 Schakman O, Gilson H, de CV, Lause P, Verniers J, Havaux X et al. Insulin-like growth factor-I gene transfer by electroporation prevents skeletal muscle atrophy in glucocorticoid-treated rats. Endocrinology 2005; 146: 1789-1797.

86 Fattori E, Cappelletti M, Zampaglione I, Mennuni C, Calvaruso $\mathrm{F}$, Arcuri $\mathrm{M}$ et al. Gene electro-transfer of an improved erythropoietin plasmid in mice and non-human primates. J Gene Med 2005; 7: 228-236.

87 Babiuk S, Baca-Estrada M, Foldvari M, Storms M, Rabussay D, Widera $\mathrm{G}$ et al. Electroporation improves the efficacy of DNA vaccines in large animals. Vaccine 2002; 20: 3399.

88 Quintana FJ, Rotem A, Carmi P, Cohen IR. Vaccination with empty plasmid DNA or CpG oligonucleotide inhibits diabetes in nonobese diabetic mice: modulation of spontaneous 60-kDa heat shock protein autoimmunity. J Immunol 2000; 165: 6148-6155.

89 Quintana FJ, Carmi P, Cohen IR. DNA vaccination with heat shock protein 60 inhibits cyclophosphamide-accelerated diabetes. J Immunol 2002; 169: 6030-6035.

90 Seifarth C, Pop S, Liu B, Wong CP, Tisch R. More stringent conditions of plasmid DNA vaccination are required to protect grafted versus endogenous islets in nonobese diabetic mice. J Immunol 2003; 171: 469-476.

91 Filippova M, Liu J, Escher A. Effects of plasmid DNA injection on cyclophophamide-accelerated diabetes in NOD mice. DNA Cell Biol 2001; 20: 175-181. 